\title{
FRONTERAS Y ESPACIOS DE RESISTENCIA EN FRUTA PODRIDA DE LINA MERUANE
}

\author{
Alena Bukhalovskaya \\ Universidad Autónoma de Madrid \\ Madrid, España \\ alenbukh@ucm.es
}

\section{RESUMEN / ABSTRACT}

La novela Fruta podrida (2007), de la escritora chilena Lina Meruane, narra la situación económico-social del Chile de la postdictadura, afectado por las violentas políticas neoliberales. En este trabajo se pretende analizar las fronteras presentes en la obra y cómo los personajes se enfrentan a estas, es decir, cómo afectan a sus vidas y sus cuerpos, siguiendo las categorías de análisis propuestas por Humberto Félix Berumen en su obra Las fronteras en el centro. Ensayos sobre literatura (2005). De acuerdo con Berumen, la noción de frontera se convierte en una herramienta fundamental para el análisis literario, por ello, es necesario abordar los textos desde esta perspectiva, con el objetivo de estudiar cómo pueden incorporarse las fronteras a las producciones literarias y cómo pueden transgredirse sus límites en la escritura.

PALABRAS ClAVE: Lina Meruane, frontera, resistencia, cuerpo, literatura chilena contemporánea.

\section{FRONTIERS AND RESISTANCE SPACES IN FRUTA PODRIDA BY LINA MERUANE}

Lina Meruane's novel Fruta podrida (2007) narrates the social-economic situation of the Chilean post-dictatorship, affected by the violent neo-liberal politics. This paper aims to analyse the frontiers present in the book and how the characters face them, how they affect their lives and their bodies, following the categories of analysis proposed by Humberto Félix Berumen in Las fronteras en el centro. Ensayos sobre literatura (2005). According to Berumen, the notion of frontier becomes an important tool of literary analysis, therefore, it is necessary to read texts from this perspective, in order to study how frontiers can be incorporated into literary productions and how they can be transgressed in writing.

KEYWORDS: Lina Meruane, frontier, resistance, bodies, Chilean contemporary literature. 
Este artículo se propone estudiar las distintas fronteras que se presentan en la obra Fruta podrida (2007) de la escritora chilena Lina Meruane. Esta autora vivió su niñez y adolescencia bajo el régimen militar pinochetista y "forma parte de las escritoras que surgieron de los talleres literarios de Diamela Eltit" (Zheng 352), donde publica sus primeras obras (Zamorano 28), hitos biográficos que marcarán profundamente su narrativa. Meruane y sus contemporáneas fueron reconocidas por el canónico Roberto Bolaño en "Fragmentos de un regreso al país natal", donde escribe:

hay una generación de escritoras que promete comérselo todo. A la cabeza, claramente, destacan dos. Estas son Lina Meruane y Alejandra Costamagna, seguidas por Nona Fernández y por otras cinco o seis jóvenes armadas con todos los implementos de una buena literatura. [...] Las jóvenes escritoras chilenas escriben como demonias (67).

Lina Meruane es autora de novelas como Póstuma (2000), Sangre en el ojo (2012) y Sistema nervioso (2018), además de otras obras como la diatriba Contra los hijos (2014) y el libro de ensayos Viajes virales: la crisis del contagio global en la escritura del sida (2012), entre otros. Sus obras poseen la intención de expresar contenidos teóricos y políticos contemporáneos a través de la intimidad de la vida cotidiana. Porque, de acuerdo con Sergio Rojas, lo cotidiano es "el corazón de lo real, en donde todo está sucediendo" (239), la vida del sujeto se desarrolla no en la Historia hegemónica con mayúscula, sino en la intimidad más inmediata, en la memoria individual construida en la pura cotidianeidad. Mediante una narrativa experimental, Lina Meruane trata de reflexionar en torno a conceptos teóricos como la biopolítica elaborada por Foucault, la noción de cuerpos que importan, planteada por Judith Butler o la enfermedad como metáfora de la patología social, sugerida por Susan Sontag. De acuerdo con Mónica Barrientos, Fruta podrida es una novela en la que "se puede reconocer la conformación de una sociedad de control que encuentra en el capitalismo su modelo ideal de desarrollo" (122). El control que menciona Barrientos se articula sobre las subjetividades de los individuos y, también, sobre sus cuerpos, que se convierten en una herramienta de producción más dentro del sistema capitalista sobre la que el Estado puede ejercer su poder.

Fruta podrida narra las vivencias de dos "medio hermanas", María y Zoila, que encarnan dos discursos diferentes: el de la productividad y la salud frente al de la improductividad y la enfermedad. María vive integrada en el sistema, posee un cuerpo sano, que se encarga de cuidar mediante la higiene 
y la automedicación, trabaja en la fábrica exportadora de fruta, encargándose de erradicar las plagas que puedan amenazar la cosecha y además se encuentra constantemente embarazada para vender sus fetos al hospital, con el fin de costear el tratamiento de su hermana. Por ello, María es doblemente productiva. Zoila, por el contrario, es completamente improductiva desde el punto de vista socioeconómico. Nunca trabaja a causa de la diabetes. La enfermedad, por tanto, la exime de pertenecer al engranaje del capital. Tampoco se integra en el sistema médico, ya que lo rechaza constantemente. Así lo explica Zoila en la novela: "mi hermana y yo vivimos en trincheras opuestas de este campo de infinita producción y reproducción” (Meruane, Fruta 73).

El control del Estado y las subjetividades predominantes favorecen al establecimiento de fronteras, tanto físicas como simbólicas, que constriñen la voluntad del individuo y segregan a los distintos grupos sociales, culturales y políticos. Asimismo, de acuerdo con Humberto Félix Berumen, el concepto de la frontera se convierte en una herramienta fundamental para el análisis literario, debido a su incorporación a la escritura posmoderna y a los estudios culturales. La frontera implica un límite y un espacio que abre una herida en el individuo y crea inexorablemente una situación de otredad (Berumen 119). Esto es, lo que se encuentra a los lados de su límite es necesariamente diferente, algo que puede causar conflictos, pero, también, conexiones e interacciones. La frontera actúa como punto de cruce entre culturas, ideologías y formas de vida, pero también como un obstáculo difícil de transgredir. Además, implica "una perspectiva, un modo particular de 'mirar', sin duda propicio para captar aspectos nucleares de nuestro tiempo" (Jiménez de Báez 323). Lo que permite, en definitiva, que se convierta en metáfora y en un recurso literario prolífico.

Berumen distingue cinco tipos de fronteras en los textos (124-5). La frontera geopolítica es aquella que hace referencia a un contorno territorial físico. Este límite puede constituirse como un espacio de ficción para el desarrollo de una obra literaria, en cuyo caso, se convierte en una frontera textual, es decir, en un espacio narrativo que se asume en el texto como un cronotopo, un lugar imaginario. A su vez, el territorio actúa de contexto para otro tipo de límites de carácter más sociopolítico, es decir, para aquellas fronteras que se construyen a partir de las diferencias que asumen los individuos, establecidas en función de su posición en el entramado socioeconómico y de sus relaciones con otros grupos sociales. La configuración jerárquica de la sociedad implica, pues, la institución de las fronteras simbólicas, aquellas que separan a los seres humanos por género, etnia, posición social, política, cultura, etcétera. 
A su vez, los propios textos literarios marcan otras dos fronteras. Por un lado, las genéricas, que se establecen en el acto mismo de la escritura, es decir, se reflejan en la forma de escribir que integra los límites de lo establecido tradicionalmente. Esta frontera discursiva se transgrede cada vez más en las obras literarias de la actualidad. Son las obras escritas en los márgenes del lenguaje las que incorporan ciertas innovaciones formales y genéricas, experimentando con la mezcla de géneros o con la deconstrucción de estos, como un acto de rechazo a las convenciones asentadas en el canon literario. Por otro lado, se encuentran las fronteras de la fantasía, esto es, los límites constituidos en la imaginación del individuo, pero los relatos actuales exploran diferentes realidades, ampliando, de esta manera, los planos de la fantasía.

La frontera se hace presente de forma explícita en los textos, ya sea como un espacio real, ficcional o como metáfora, y se articula, de esta manera, como referente y tema que se refleja en las vivencias de los personajes y en el propio lenguaje con el que se constituye la obra. La literatura posee, pues, la capacidad de desestabilizar las fronteras, ya que las vuelve permeables. Así, pues, algunos autores las transgreden en sus obras, de lo que la novela de Lina Meruane es un claro ejemplo. Los personajes de Fruta podrida se encuentran con distintas fronteras, simbólicas y geopolíticas, además de que el propio lenguaje de la obra transita por los márgenes genéricos de la narrativa. En consecuencia, de acuerdo con Estefanía Bournot, "vemos las fronteras no como obstáculos sino como figuras liminares, que ponen en contacto territorios, que dan inicio a un recorrido" (146). El propio concepto de frontera se desplaza entre la idea de límite y la del intercambio (Jiménez de Báez 326).

\section{FRONTERA GEOPOLÍTICA Y TEXTUAL}

Si bien es cierto que la novela se situa en Ojo Seco, un pueblo circunscrito al espacio fabril del galpón, que se encuentra en Chile, la forma de vida de los personajes que se describe en la obra es global, ya que está atravesada por el neoliberalismo despiadado y su control. De este modo, la narracion se situa en un lugar concreto, pero podría extrapolarse a todo el orbe, "no importa la ubicación real, Ojo Seco es el mundo actual" (Barrientos 123). Esto es, la doctrina del capitalismo circula a lo largo de todo el territorio global, arrasando con las fronteras geográficas mediante los medios de comunicación universales, que reproducen un mismo esquema sociocultural 
de comportamientos y formas de vida normativizadas. A su vez, el Norte simboliza el centro neurálgico de la producción y de la productividad, es el lugar que habita el Padre, símbolo del poder patriarcal y del capital, y es el espacio que exporta tecnología y saber médico al Sur. La innovación y el progreso vienen del Norte, configurando una economía dependiente de importación y exportación que establece una relación de neocolonialismo. Por las coordenadas espaciales y las características que Lina Meruane aporta en su novela, es posible inferir que el Norte hace referencia a los Estados Unidos de América del Norte, ya que se configura como una potencia económica, tecnológica y colonizadora que invade el Sur. Algunos investigadores, como Mónica Barrientos, han concretado incluso que la ciudad a la que viaja Zoila es Nueva York (123).

Zoila no se percibe como un peligro cuando entra en los EE. UU., esto es, cuando atraviesa la frontera geográfica que separa el norte del sur, viaja con el pasaporte de su hermana, la maleta llena de dólares, su "cuaderno deScomposición" y su enfermedad. Todo lo que declara cuando ingresa al país es falso (Meruane, Fruta 120). Resiste con un lenguaje que se vuelve ininteligible y despreciable para la ley dominante, por eso la dejan entrar. Por eso nadie la piensa como sospechosa (Recchia Paez 166), igual como ocurre con los ciegos que protestan en la plaza de Ojo Seco: solo Zoila conoce el peligro que estos hombres sin nada que perder pueden suponer. La Menor se exporta, pues, infectada para tratar de proporcionar a los enfermos lo que ella no tuvo: la posibilidad de decidir si quieren o no aceptar un tratamiento que los mantiene "pinchados, drenados, adelgazados, deteriorados, sentenciados a vivir así y sin derecho a discrepar" (Meruane, Fruta 129). Esta frontera geográfica es transgredida, pues, por Zoila sin apenas dificultades, no es tanto un obstáculo que se debe superar, sino una metáfora, un espacio narrativo cargado de significado simbólico. El Norte se llena de sentido, crea un conflicto en el individuo, causa una situación de otredad y de inferioridad para aquellos que se encuentran al Sur, para aquellos que poseen una economía y un sistema médico dependiente.

Asimismo, la novela se desarrolla en torno a otros dos espacios fundamentales de producción y reproducción que se van alternando. Por un lado, se encuentra el galpón, la fábrica de fruta donde trabaja la Mayor encargándose de erradicar las plagas que puedan afectar a las exportaciones frutales. Y, por otro lado, aparece el hospital como espacio de reproducción, vigilancia y control, al que María vende los fetos que tiene consecutivamente, para recibir una remuneración económica y para costear la supuesta cura de 
Zoila. Las hermanas acuden periódicamente al hospital, para los partos de María y para los reconocimientos médicos del estado de Zoila. El hospital actúa como el "lugar central de disciplinamiento y normalización para crear frutas y cuerpos productivos" (Barrientos 95). A su vez, el espacio privado de la casa que habitan las dos hermanas se contamina por los flujos de poder de la sociedad, esto es, se produce un panóptico, en términos foucaultianos, es decir, una reproducción de esquemas jerárquicos del exterior en el interior privado de la institución familiar. Guadalupe Santa Cruz habla de la "casa faenada", aquella casa que se adosa directamente a la fábrica y "donde el cuerpo de las mujeres se sabe ya un engranaje en la cadena productiva" (97). En consecuencia, la Mayor trata de aplicar el control del sistema médico en el interior de la casa sobre su hermana Zoila, mediante la imposición de los cuidados, que la Menor rechaza categóricamente.

Los lugares que se presentan en la novela se someten al orden capitalista: el galpón, el hospital y la casa de las hermanas. Este sometimiento constante, en lo público y lo privado, crea un sentimiento de dependencia que obliga a atacar cualquier posibilidad de dislocación del proceso de consumo (Zamorano 33). El cuerpo se convierte en otro espacio que experimenta una imbricación paralela con el sistema capitalista, ya que este se sustenta sobre la biopolítica, esto es, los cuerpos se insertan en el aparato de producción mediante los ajustes de población y la implantación de la salud como bien supremo para asegurar la utilidad de las fuerzas de trabajo (Oreja 4). La identidad alienada del individuo se hace inseparable de su puesto de trabajo, "los uniformes que cuelgan como hermanas vacías en el armario" (Meruane, Fruta 100). "La entrega absoluta y obligatoria al trabajo, así como el miedo constante al despido [...] generan relaciones basadas en la desconfianza y en la traición de unos a otros" (Oreja 4). Debido a dicho miedo, María acaba con la revuelta de las temporeras, creyendo pertenecer a un sistema que la va a recompensar por su fidelidad. Sin embargo, se da cuenta de que la empresa es igual de cruel con ella que con sus compañeras, por mucho que sacrifique su vida y su tiempo por el trabajo. De acuerdo con Zamorano, "todos los lugares en que se desarrolla la trama de la novela, la empresa de exportación, el hospital, la casa, son espacios que se superponen y se someten a una economía global de la eficiencia y la sumisión irrestricta a un orden, a una racionalización de las experiencias humanas" (33).

De esta manera, el espacio se erige como una categoría fundamental para la configuración de la subjetividad de los individuos contemporáneos, ya que el objetivo del disciplinamiento biopolítico es, precisamente, distribuir 
a los individuos en el espacio y en el tiempo. Este espacio, de acuerdo con Foucault, debe ser clausurado y celular, esto es, contendrá varios espacios en los que cada individuo deberá realizar su tarea, cada emplazamiento será ocupado por un solo sujeto, porque las agrupaciones son peligrosas; así, el poder ejercido por el sistema se vuelve más exhaustivo y estos territorios son siempre funcionales, es decir, útiles y efectivos para la administración de los cuerpos (cit. en Oreja 5). Las fronteras entre lo público y lo privado se hacen permeables. Así pues, los esquemas laborales represivos por un proceso panóptico se trasladan al núcleo familiar que en la novela se presenta desestructurado. La madre de las dos medio hermanas nunca aparece, el único dato que el lector conoce de ella es que es o fue "una mujer local". La única figura paterna es el padre de Zoila, un empresario extranjero que se ha marchado, dejando a María en el puesto del galpón y a cargo de los cuidados de la Menor. La ideología dominante se reproduce dentro de la institución familiar, donde el esquema de consumo y represión se impone por las figuras de poder.

En definitiva, las fronteras espaciales de la novela no se presentan como estamentos rígidos, sino como límites permeables, atravesados por el control y la represión sistémicos. Las vidas de los sujetos son invadidas y subyugadas por los aparatos de Estado, el control militar en el galpón, los tratamientos violentos del hospital, los exámenes invasivos del Enfermero, la autoridad de María dentro del hogar... Todo ello crea un espacio violento en el que el individuo ha de desarrollar su subjetividad. La configuración del espacio condiciona al individuo y, por ello, los sujetos sociales se construyen con una variedad de discursos, de tiempos y de espacios. En definitiva, las relaciones de poder atraviesan cuerpos geográficos y cuerpos físicos (Barrientos 93).

\section{FRONTERAS SIMBÓLICAS}

En la novela se presenta una dicotomía entre las posturas que pueden asumirse frente al sistema, encarnadas en las dos medio hermanas que protagonizan la obra. Por un lado, se presenta el cuerpo de María y su relación con el sistema económico, que al comienzo de la novela es de sumisión, y, por otro, se encuentra el cuerpo de Zoila y su resistencia contra el sistema médico, que le impone tratamientos imposibles de seguir, además de la aversión y del rechazo que sienten ambas mujeres a ejercer o aceptar los cuidados familiares. Las dos hermanas presentan discursos diferentes: 
mientras la Menor es consciente de las trampas de la biopolítica, de sus exclusiones, y se resiste a ellas desde una autodestrucción que representa el fracaso de la institución médica y por extensión del Poder; la Mayor cree que conseguirá superarlas, reescribiendo el lenguaje de la maternidad para hacerlo productivo y no afectivo, ocupando un cargo de química pesticida poco habitual para una mujer (Ferrús 330).

Las dos mujeres se encuentran, pues, en lados opuestos de una frontera que separa los cuerpos productivos de los improductivos, los cuerpos útiles de los inútiles, en suma, los cuerpos sanos de los enfermos. La salud del cuerpo productor o reproductor es esencial para el funcionamiento del engranaje económico. Por ello, "toda enfermedad, toda herida, es una transgresión de las fronteras del espacio corporal, más o menos dolorosa y más o menos profunda, que 'abre' el espacio clausurado del cuerpo" (León 55). Ya que un cuerpo enfermo se considera como un estado "anormal", que debe ser normativizado, así pues, se permite el acceso invasor y abusivo del sistema médico hacia dicho cuerpo para tratar de normalizar lo "defectuoso", que implica que el individuo ya no sirve o no sirve tan bien como herramienta para el capitalismo. Así, la finalidad última de las instituciones clínicas no es mantener cuerpos sanos, sino cuerpos controlados que sirvan al sistema represivo (Barrientos 94). Según afirma Foucault, "los dispositivos de poder se articulan directamente en el cuerpo" (cit. en Ferrús 328). La biopolítica es la consideración que toma el poder de la vida de los individuos e incide directamente en ella, mediante la ideología y los aparatos de Estado. De este modo, el cuerpo se define en primera instancia como cuerpo de trabajo; no existen los sujetos para el sistema, sino solo cuerpos útiles para la producción y la reproducción.

El tema de la enfermedad y la patología es fundamental tanto en el discurso político como en el discurso literario, entendidos estos como conformadores de subjetividades. La salud y la enfermedad son determinadas desde y hacia el cuerpo social. El individuo se reduce a estados de productividad o de estorbo al trabajo, y la medicina recibe el encargo de rescatar al trabajador recuperable, abandonando a quienes no son productivos (Kottow 131). El concepto de vida para el sistema médico es limitado, implica una serie de constantes vitales que establecen la condición de no-muerte y este estado se mantiene mediante prácticas médicas asociadas al cuerpo como sistema. La amenaza de la enfermedad y de la muerte legitima el discurso clínico 
(Recchia Paez 160). Una vez erigida la salud en tanto valor supremo a ser constituido y preservado, la enfermedad se convierte en un fenómeno de gran alcance metafórico, como proyecto de resistencia. La metáfora de la enfermedad en la literatura se relaciona con la espacialidad, ya que un cuerpo enfermo difumina o reafirma las fronteras existentes entre los enfermos y los sanos. Este binomio se plasma en la fruta, la fruta podrida no puede ser exportada y, por ende, debe ser desechada. La patología como metáfora sirve para crear discursos que problematizan las contradicciones del poder. Por ende, siguiendo a Kottow,

la enfermedad, en tanto cifra de lo distinto, se establece como plataforma simbólica desde la cual cuestionar y deconstruir la lógica moderna de la razón. La enfermedad se vuelve portadora de un saber y una gramática distinta que, a su vez, logra mostrar las falencias del discurso racionalizador y saludable (145).

La identidad abyecta puede entenderse como una copia fallida del ideal sistémico, que a su vez representa una línea de fuga y de subversión no organizada inherente siempre al sistema (Oreja 6). Así pues, el cuerpo enfermo posee la capacidad de desarticular la frontera mediante la disidencia al margen del discurso hegemónico y de proponer una forma de vida distinta que se encuentre apartada del dictamen del sistema capitalista.

La enfermedad y la escritura se convierten en dos formas básicas de resistencia. Zoila lucha por decidir sobre su propio cuerpo; al margen del tratamiento impuesto, boicotea su propia salud. Cuanto más avanzada la enfermedad, más dueña se siente de sí misma, ya que la diabetes forma parte de ella. Al final, la acepta como inevitable y construye de esta manera su propia identidad. La diabetes es suya y es ella quien elige seguir comiendo dulces y fumar del cigarro del Enfermero, aunque la haga marearse y ver todo aún más borroso. La enfermedad es, en suma, una forma de disidencia. Zoila encarna un concepto de vida diferente, una vida propia marcada por la enfermedad, ininteligible desde el saber médico. Una vida improductiva de quien acepta la muerte como una posibilidad. De acuerdo con Keizman, lo viviente ampliado que se presenta en esta obra incluye lo podrido (112), la muerte forma parte de la vida, difuminando la frontera entre vida y muerte. La Menor reivindica su derecho a la muerte, lejos de aceptar la inmortalidad que ofrece el sistema médico, aquella inmortalidad que implica la inhumanidad y la sumisión a la medicina. En la podredumbre de Zoila 
late el deseo propio, "un nihilismo del libre albedrío que resiste al control biopolítico" (Keizman 113).

El cuerpo enfermo, a su vez, sirve en Fruta podrida de metáfora para reflejar la situación sociopolítica del Chile de postdictadura, un contexto de explotación con salarios muy bajos y condiciones laborales pésimas de los temporeros chilenos. Citando a Fallas Arias, las políticas neoliberales adoptadas durante la dictadura de Pinochet perjudicaron enormemente a la economía y a la población chilenas, pero beneficiaron a las corporaciones internacionales (4). Los sujetos más perjudicados en este contexto fueron las mujeres, que no solo se encontraron sujetas a la dominación social, sino también al sistema opresor de las fábricas, que las excluye de todo tipo de derechos y garantías laborales, además de obligarlas a llevar a cabo su trabajo en unas condiciones deplorables (Fallas 5). En suma, las mujeres obreras experimentan la represión tanto en su puesto de trabajo como en la privacidad de sus hogares, además de estar obligadas a realizar una doble jornada laboral: "las temporeras estaban solas, solísimas, sin compañeros, se habían ido quedando sin sus hombres, sin sus maridos, sin los padres de la prole, porque ellos estaban cesantes o alcoholizados o vagando por las calles, y no contaban con ellos" (Meruane, Fruta 92).

María presenta una dependencia total al sistema laboral donde pertenece, "que estructura casi por completo su subjetividad" (Zamorano 30). Esta obediencia y conformidad de María con el sistema es lo que erige una sólida frontera entre las dos hermanas. La Mayor no comprende la actitud suicida de la Menor y Zoila no puede aceptar la forma de vida de su hermana sumida en el engranaje de producción, en definitiva, en el mercado. De acuerdo con Louis Althusser, "nada escapa al capitalismo" (31), porque este no ejerce una violencia física directa, sino que su discurso se diluye en rituales de consumo y repetición mediante el artificio y el espectáculo. El control se hace, en apariencia, más democrático y, en consecuencia, siguiendo a Foucault, el poder no actúa sobre el individuo concreto, sino sobre el ser humano como especie: "se ejerce en el nivel de la vida, de la especie, de la raza y de los fenómenos masivos de población" (cit. en Zamorano 31). Esto es, la religión del capital dicta cómo ha de desarrollarse la vida de todo ser humano. Por consiguiente, actúa sobre el plano del deseo, de la subjetividad. Así pues, como se ha señalado en el apartado anterior, la jerarquía y la represión del poder penetran en la esfera privada de la vida, afectando de esta manera ya no solo el cuerpo del sujeto trabajador, esto es, el individuo que se encuentra en la máquina de producción, sino a todos los seres humanos. El poder produce 
a los sujetos que controla, pero, a su vez, el discurso de la represión crea puntos de resistencia.

Así mismo, el cuerpo femenino posee diversos tipos normalizados en el discurso hegemónico del poder: la figura de la madre, la amada sumisa o la amante sensual, la joven virgen, etcétera. Las figuras femeninas en la novela de Lina Meruane tratan de oponer resistencia frente a las instituciones disciplinarias y no encajan en los moldes tradicionales establecidos para las mujeres. Si bien es cierto que el cuerpo femenino se encuentra subordinado al control del Estado y de la ideología, es también el arma para resistir a dicho control. El cuerpo permite dejar en suspenso y desarticular las subjetividades del capitalismo. El lenguaje del cuerpo femenino se desarrolla mediante la sangre, como en la huelga de las temporeras, en las lágrimas, la enfermedad y la diabetes de Zoila, en el dolor y la maternidad. La Mayor no se da cuenta de que el sistema es igual de cruel con ella que con las demás hasta que traiciona a sus compañeras de trabajo y no obtiene nada a cambio. Es entonces cuando decide rebelarse contra la empresa de fruta, contagiada, según las palabras de Lina Meruane, por el espíritu disidente de Zoila ("Todo" 1). Las dos hermanas se unen en la lucha contra el sistema, cada una a su manera, y se vuelven prácticamente una sola mujer, una mujer que es a su vez todas las demás mujeres. Las rebeliones de María y Zoila, aunque fallidas, son la única forma de resistencia contra el poder represivo del sistema. La Menor, a su vez, se resiste al molde del cuerpo femenino enfermo, que no se presenta como inválido, sufriente ni vulnerable, sino como pura potencia para la disidencia. Bajo la estricta vigilancia del sistema médico, la Menor se configura como un cuerpo viviente que opone resistencia a su "inscripción en el entramado de las patologías" (Quintana 128).

La maternidad en la novela se desarticula, se convierte en un acto productivo y no reproductivo. María obtiene beneficios económicos por vender los fetos que produce cada nueve meses al hospital para la experimentación y para trasplantes. María no es la única mujer que lleva a cabo esta labor, algunas de las temporeras también venden a sus recién nacidos para la exportación. Zoila, en cambio, posee un cuerpo que nunca ha producido nada, porque "ha sido privilegiada con un cuerpo enfermo" (Meruane, Fruta 172). Lo que lleva a la enfermera a afirmar que ni siquiera es una mujer, porque el deber de todas las mujeres es la reproducción. El cuerpo enfermo se convierte un privilegio, debido a que exime al individuo de trabajar y a la mujer de su rol social y biológico de madre reproductora. Zoila no es madre, por lo que, según la enfermera, apenas es mujer: es una poeta enferma, una vagabunda 
sin nombre, cuyo cuerpo descompuesto yace en la calle cubierto de nieve en un banco frente al Gran Hospital. Zoila no existe en los registros médicos de la enfermera. Es una no ciudadana en los EE. UU., pues todos los datos que proporciona al entrar al país son falsos. No tiene a nadie que la recuerde o que pueda llorar su muerte. Es insignificante, porque se encuentra fuera del sistema capitalista, fuera de los registros médicos, sin pasaporte, sin identidad registrada, sin haber producido nunca nada, en definitiva. En términos de Butler, la suya es una "vida precaria" que no importa desde la perspectiva de la sociedad del capital: al no encajar en los parámetros de lo inteligible, Zoila no es "un actor viable" dentro del sistema (cit. en Oreja 8). La Menor propone, según Keizman, una política de la detención y de la contemplación frente a la "febril actividad de[1] sistema [que] aspira a erradicar la muerte" (113), se asienta en un lapsus improductivo, suspendido al margen de la aceleración productiva contemporánea. Zoila es un presente detenido en la resistencia.

En consecuencia, las protagonistas están marcadas por su género, por pertenecer a la clase obrera, por la dependencia del sistema médico y por no contar con la protección masculino-paterna -aunque la figura del Padre acecha y condiciona sus vidas, nunca llega a aparecer en la novela-. La identidad no es un compartimento estanco ni uniforme, sino que se configura mediante variables de carácter social, económico, cultural, de género, etcétera. Las distintas identidades crean fronteras en torno al individuo y condicionan sus relaciones sociales, pero también poseen la capacidad para desarticularlas, mediante la marginalidad y la disidencia. El cuerpo es el último reducto de resistencia ante la dominación del mercado y de la lógica capitalista a la que este sirve. El avance de la enfermedad de Zoila deshumaniza su propio cuerpo, borra las fronteras de lo humano, haciendo que se asimile a un vegetal, especialmente en las páginas finales de la novela, donde su cuerpo informe es consumido por la podredumbre. El organismo se ve sometido a la disciplina y al control y su abandono supone un atentado contra el orden del propio cuerpo (Oreja 9). Así, el atentado contra el organismo se convierte en una forma de vida, en una forma de atentar contra la represión biopolítica del sistema.

En torno al cuerpo de Zoila se construye una estética de la tensión, que produce, en términos de Bourriaud, una "exforma": un cuerpo que resiste a toda forma (cit. en Quintana 130). El de Zoila ya no es un cuerpo vivo, porque está afectado por la podredumbre que le corroe los pies; pero tampoco es un cuerpo muerto, ya que resiste hasta el final. Así pues, es un cuerpo no clausurado, un cuerpo incompleto y enfermo que no encaja en el sistema. $\mathrm{Si}$, 
de acuerdo con Jean-Luc Nancy, "el cuerpo da lugar a la existencia" (cit. en Quintana 130), ¿a qué tipo de existencia puede dar lugar un cuerpo como el de Zoila? En palabras de Quintana, el cuerpo putrefacto de la Menor articula "una vida vaciada de todo imaginario de la completitud" (130), esto es, una existencia que corroe los circuitos de representación hegemónicos y que articula su propio lenguaje, en este caso mediante el idioma del organismo. "El cuerpo de Zoila desaparece pero no termina, es ese resto que emerge impidiendo su cerramiento, no hay punto final" (Quintana 131). Zoila es inasimilable, porque es ajena a los moldes habituales de las instituciones, su cuerpo es indigesto, como la fruta envenenada por María, pero sigue siendo potencia, sigue siendo un cuerpo viviente que emerge para anunciarse como una forma alternativa de vida, de una vida sin clausura, porque es la vida del resto, una vida que es también muerte y podredumbre.

\section{FRONTERAS GENÉRICAS}

Lina Meruane, de acuerdo con Simone Fenna Walst, tiene una forma experimental y original de narrar la enfermedad en sus obras (4), recurriendo a diversos recursos como la autoficción y el lenguaje fragmentario, tanto en el nivel de la sintaxis, como en el del propio género, dentro del que puede irrumpir, por ejemplo, la poesía. El cuerpo patológico se proyecta en un lenguaje descompuesto. La enfermedad se presenta desde las primeras líneas como una invasión violenta del cuerpo, que influye en las vidas de los individuos de manera significativa. Susan Sontag señala que la enfermedad actualmente se concibe de manera militarista como una "invasión del cuerpo", que significa un peligro para la salud normalizada del organismo (cit. en Walst 6).

La novela, según Beatriz Ferrús, se divide en tres niveles discursivos. El primero es la historia de las hermanas, que combina la primera, la segunda y la tercera personas. "El segundo nivel pertenece al 'cuaderno deScomposición' que escribe Zoila y está conformado por los nueve poemas que puntúan los diferentes episodios de la historia central" (334). El tercer nivel sería la última parte de la novela, el monólogo "desquiciado" de la enfermera. Este último discurso está inserto en el poder, en el sistema médico. La enfermera se queja de la represión laboral que experimenta, en tanto ella ni siquiera puede ponerse enferma, ya que no hay lugar para una enfermera enferma en las salas de espera de urgencias (Meruane, Fruta 114). Por ello, interroga 
a Zoila, convertida en mendiga, que resiste en silencio, salvo en ocasiones puntuales, en las que la enfermera apenas la entiende.

El texto de Meruane es una denuncia, pero no es pura teoría. Está muy cerca del lector y de su realidad y, sin embargo, a causa de la experimentación formal y del lenguaje desarticulado, siguiendo a Ferrús, se promueve

en el lector la imposibilidad de identificación con los personajes por la vía de la hipérbole, el juego de sensaciones, pero también la parábasis que trunca la lectura realista, lo empuja a la autorreflexión sobre el desasosiego que provoca Fruta podrida, pero también lo obliga a mirar la forma, a preguntarse por el vehículo (el lenguaje) que pone en circulación los interrogantes y la denuncia, convirtiendo este gesto en una forma de subrayado. Sin olvidar también que el lenguaje es un arma poderosa, que tiene poder performativo y que pararnos a pensar sobre él es siempre un acto político (335).

Así pues, el propio lenguaje se pone a prueba en Fruta podrida, buscando desarticular el discurso hegemónico y tradicional y rompiendo la frontera genérica de la narrativa convencional, mediante la prosa poetizada y la irrupción de los versos del "cuaderno deScomposición" que escribe Zoila sobre la historia de su padecimiento, una vez agotada la lengua de la prosa. La novela logra transmitir la angustia de la enfermedad, la desolación de la soledad que sienten las dos hermanas, la incomprensión que sufre Zoila y la represión del tratamiento médico, todo ello mediante un lenguaje dislocado y político. La sintaxis tradicional se descompone en los márgenes del discurso literario. La vía de escape de Zoila es la poesía, un género que la enfermera califica de improductivo e inútil. "En los capítulos escritos en prosa, Zoila no habla, sino que resiste en silencio" (Novelli 293). La poesía se comprende como el límite del lenguaje; por la musicalidad y los silencios la lengua de los versos no puede traducirse al lenguaje de lo útil, "esa lengua dentro del discurso del poder se vuelve imposible" (Novelli 294). El lenguaje no tiene por qué ser siempre comunicación, ya que tiene sus propios límites y precisamente la descomposición del lenguaje testimonia aquello que es imposible narrar. Con la poesía la comunicación se suspende. "El individuo debe desubjetivarse como ser real para pasar a ser el sujeto de la enunciación que nos propone el lenguaje e identificarse con ese 'yo' del que intenta apropiarse" (Novelli 295).

La poesía de Zoila oscila entre la vida y la muerte, poetiza un cuerpo patológico donde todo es potencia para la disidencia. El ser real se convierte 
en silencio, ese silencio que es límite del ser y del lenguaje. La de la enfermera es la voz de la productividad y del control de la biopolítica de los que Zoila quiere huir, separándose del discurso médico. Finalmente, la voz de la Menor y su cuerpo se descomponen, el cuaderno se deshace sobre su piel bajo el abrigo. La enfermera exclama ante el cuerpo moribundo de Zoila unas palabras demoledoras: "qué mendiga de mierda, y encima poeta" (Meruane, Fruta 184). La novela la coloca, de esta manera, en el mundo de los improductivos. En este punto, el propio lenguaje se encuentra con una frontera: cómo nombrar lo marginal, lo que se sale de la gramática hegemónica. De acuerdo con Beatriz Ferrús, el estilo narrativo de Lina Meruane es experimental y creativo (327) precisamente al explorar la posibilidad de narrar lo que no se puede narrar mediante la lengua normativa del sistema.

La escritura se presenta, pues, como una forma de resistencia. Zoila logra superar el silencio en las páginas de su "cuaderno deScomposición”, utilizando un elemento perteneciente a su tratamiento para desarticularlo mediante sus propios medios. Toda Zoila se encuentra fuera del ámbito de lo productivo: además de poseer un cuerpo enfermo y de dedicarse a escribir versos inútiles, es una mujer que rechaza la maternidad y la imposición de los cuidados; ni los ejerce, ni los quiere recibir. De acuerdo con Fallas Arias,

Meruane desencadena la subversión de Zoila, quien se niega a registrar en los cuadernos de composición "la comida, la dosis, los colores desplegados por las tiras reactivas en la orina" (Meruane, Fruta 41), para saturarlo con palabras sueltas, recortes de noticias $\mathrm{y}$ frases de las que emergen poemas, como un acto de rebeldía y de resistencia al poder (21).

\section{CONCLUSIONES}

En definitiva, Lina Meruane narra en Fruta podrida "el drama vivido en Chile bajo la implementación salvaje de la economía de mercado que atacó, de manera siniestra, los campos y los cuerpos" (Ferrús 26). Mediante el personaje de Zoila, que posee una identidad y un cuerpo abyectos que la sitúan fuera del discurso hegemónico, se propone una nueva forma de vida, al margen del dictamen del sistema sobre qué cuerpos importan y qué vidas merecen ser vividas. La Menor resiste para articular su propio lenguaje, reivindica la vida, una vida construida en torno a las pulsiones del cuerpo, que rechaza todo 
tratamiento médico. Se desarticula de esta manera la frontera que separa los cuerpos enfermos de los cuerpos sanos, porque el cuerpo diabético de Zoila acepta la enfermedad, la podredumbre y la muerte como parte de la propia vida. Dicha frontera segrega a los sujetos productivos insertos en el sistema frente a los sujetos improductivos, inválidos, inútiles, que poseen una vida precaria, que no merece ser vivida, porque no se incorpora al engranaje del capital.

Zoila encarna, en suma, un cuerpo y una identidad ininteligibles desde la lengua de la productividad. En este sentido, las dos medio hermanas se encuentran en trincheras opuestas del mundo capitalista. Sin embargo, las fronteras no son estancas ni uniformes, sino que se producen intersecciones entre las distintas características que configuran la identidad y la segregación. Si bien es cierto que en cuanto a la economía y a la medicina el discurso de las hermanas, en primera instancia, es opuesto, en otros puntos clave de su desarrollo comparten la misma circunstancia. Uno de ellos es la frontera de género. Las dos poseen un cuerpo femenino, que se encuentra bajo la represión de figuras masculinas -el Ingeniero, el Enfermero, el Médico General y el Padre-, que a su vez reciben órdenes desde el extranjero, configurando así una frontera geopolítica que se convierte en símbolo del neocolonialismo.

La categoría de "mujeres" encierra en sí misma otras fronteras que delimitan a los sujetos construidos socialmente como femeninos. De acuerdo con Judith Butler, "una es mujer en la medida en que funciona como mujer en la estructura heterosexual dominante" (12). Esta afirmación se encuentra explicitada en la novela mediante las palabras de la enfermera, cuando asevera que la mujer que comete los atentados contra el hospital ni siquiera es una mujer: es una desquiciada, "improductiva además de frustrada, una que no pudo ser madre, una abortista, una lesbiana radical disfrazada de hombre, una feminista más que una terrorista" (Meruane, Fruta 157). Todas esas mujeres que enumera no se ajustan al rol social establecido de lo que es ser mujer, al igual que Zoila: mendiga, enferma y, además, poeta. Estas mujeres "pertenecen a una especie incomprensible" (Meruane, Fruta 158) para el discurso normativo hegemónico. Las prácticas de las dos medio hermanas desestabilizan la categoría de género. María es una madre no reproductora, sino productora de bienes económicos mediante la venta de sus propios fetos, y Zoila es una mujer enferma de diabetes, que reniega de la producción en cualquiera de sus formas. Retomando las palabras de Butler en El género en disputa, la gramática y el estilo no son cuestiones políticamente neutras, ya que existe un lenguaje normalizado que configura el género y "el precio que hay que 
pagar por no conformarse a él es la pérdida de la misma inteligibilidad" (22). De esta manera, el discurso orgánico de Zoila se vuelve incomprensible para la enfermera, para la institución y, en consecuencia, para el poder.

Así pues, mediante un cuerpo sitiado y atravesado por distintas fronteras, Meruane desarticula el discurso hegemónico y hace tambalear los límites entre lo útil y lo inútil desde el punto de vista de la productividad. Si las fronteras se imponen a los seres humanos para segregarlos en distintos grupos sociales, solo un cuerpo abyecto al margen del sistema posee la capacidad de producir un desequilibrio, mediante la resistencia articulada con un lenguaje fragmentado y descompuesto, emitido desde la mendicidad, desde la enfermedad, desde la podredumbre. El cuerpo diabético de Zoila se descompone atravesando las fronteras entre la vida y la muerte, la productividad y la no productividad, el Norte y el Sur, la enfermedad y la salud, la prosa y la poesía, la palabra y el silencio.

En definitiva, la novela Fruta podrida de Lina Meruane es una obra subversiva que atenta contra el discurso hegemónico para proponer una forma de vida alternativa fuera de las fronteras impuestas por el sistema capitalista. La forma de esta novela imposibilita que el lector se identifique con los personajes, produciendo un texto incómodo de leer que obliga a tomar distancia y a reflexionar sobre la obra y su propia realidad. "Escribir desde los márgenes implica entonces no hacerlo desde las tendencias dominantes, sino más bien desde los espacios que suponen actitudes críticas que contrapunteen el canon y el poder" (Jiménez de Báez 230) y esa es precisamente la postura que adoptan Meruane y Zoila en sus escritos, una perspectiva crítica con el discurso hegemónico, que observa sus contradicciones y articula un lenguaje propio desde la frontera.

\section{BIBLIOGRAFÍA}

Althusser, Louis. Ideología y aparatos ideológicos de Estado. Buenos Aires, Nueva Visión, 1974. Barrientos, Mónica. "La fisura del espacio y la toxicidad de los cuerpos: El contagio de Guadalupe Santa Cruz y Fruta Podrida de Lina Meruane". Chasqui: revista de literatura latinoamericana 44, $\mathrm{N}^{\circ} 1,2015$, pp. 91-103.

"Sujeto, cuerpo y texto: una mirada a la producción narrativa de escritoras chilenas en los últimos años". Inti: Revista de literatura hispánica 69, 2009, pp. 115-125.

Berumen, Humberto Félix. "La frontera en el centro". La frontera en el centro. Ensayos sobre literatura. Mexicali, Universidad Autónoma de Baja California, 2005, pp. 119-149. 
Bolaño, Roberto. "Fragmentos de un regreso al país natal." Entre paréntesis: Ensayos, artículos y discursos (1998-2003). Edición de Ignacio Echeverría, Barcelona, Anagrama, 2013, pp. 59-70.

Bournot, Estefanía. "Rutas y encrucijadas: cronotopos de la narrativa contemporánea latinoamericana". Anales de Literatura Hispanoamericana 44, 2015, pp. 139-148.

ButLer, Judith. El género en disputa. El feminismo y la subversión de la identidad. Barcelona, Paidós Ibérica, 2007.

Fallas Arias, Teresa. "Fruta podrida: la reivindicación de la vida y de la muerte desde un cuerpo enfermo, desechado". Revista Humanidades: Revista de la Escuela de Estudios Generales 6, N¹, 2016), pp. 1-30.

Ferrús, Beatriz. "Fruta podrida. La escritura descompuesta de Lina Meruane." Rassegna iberistica 39, $\mathrm{N}^{\circ} 106,2016$, pp. 325-336.

JimÉNEZ de BÁEz, Yvette. "Frontera, historia y literatura.” Nueva Revista de Filología Hispánica $60, \mathrm{~N}^{\circ} 1,2012$, pp. 323-355.

Keizman, Betina. "Las dinámicas de lo viviente repetición, supervivencia y vidas potenciales." Cuatrocientos cincuenta y dos grados fahrenheit. Revista de teoría y de literatura comparada 17, 2017, pp. 102-121.

Kottow, Andrea. "Patologías deconstructivas: cuerpos enfermos y razón moderna en la literatura chilena del siglo XIX". Voz y escritura. Revista de estudios literarios 20, 2012, pp. 129-150.

LEÓN, DENISE. "El cuerpo herido. Algunas notas sobre poesía y enfermedad". Telar 10, 2012, pp. 53-74.

Meruane, Lina. Fruta podrida. Santiago, Fondo de Cultura Económico, 2007.

"Todo sobre la peste". El Mercurio 4 de noviembre de 2007, E21.

Novelli, Julieta. "Modos de resistencia en Fruta podrida de Lina Meruane". Caracol 17, 2019, pp. 284-299.

Oreja Garralda, Nerea. "Identidades abyectas como formas de resistencia no organizada en el contexto neoliberal: el caso de Mano de obra y Fruta podrida." LL Journal 12, $\mathrm{N}^{\circ} 1,2017$, pp. 1-15.

Quintana, Isabel A. "Parcelas de vida: el arte y sus restos". Cuatrocientos cincuenta y dos grados fahrenheit. Revista de teoría de la literatura y literatura comparada 17, 2017, pp. 122-138.

ReCChia PAez, JuAn. "Cuerpos infectos, cuerpos extraños: literatura y vida en Fruta podrida de Lina Meruane”. Estudios de Teoría Literaria. Revista digital: artes, letras y humanidades 7, $\mathrm{N}^{\circ} 14,2018$, pp. 155-168.

Rojas, SERgio. "Profunda superficie: memoria de lo cotidiano en la literatura chilena". Revista Chilena de Literatura 89, 2015, pp. 231-256.

Santa Cruz, Guadalupe. "Escritoras chilenas: imaginarios en torno a los espacios". Nuestra América 7, 2009, pp. 89-99.

Walst, Simone Fenna. "Ficciones patológicas: la enfermedad y el cuerpo enfermo en Fruta podrida (2007) y Sangre en el ojo (2012) de Lina Meruane". Revista estudios 31, №2, 2015, pp. 1-18. 
Zamorano, César. "Capitalismo y producción de subjetividad en Mano de obra y Fruta podrida”. Revista Iberoamericana 82, №254, 2016, pp. 27-43.

ZHENG, NAN. "La intimidad transgresora en la ficción de Costamagna, Fernández, Jeftanovic, Maturana y Meruane. ¿Podemos hablar de una nueva generación literaria?”. Revista Chilena de Literatura 96, 2017, pp. 351-365. 